\title{
Making the Power System Intelligent
}

\author{
Dr. Péter Kádár, member of IEEE \\ kadar.peter@kvk.bmf.hu \\ Budapest Tech, Dept. of Power Systems \\ Bécsi u. 94. Budapest \\ H-1034 HUNGARY
}

\begin{abstract}
The increasing power demand requires better exploitation of the existing system. A possible method is the decrease of the peak/valley ratio of the daily load curve. The intelligent applications help the control on the power system level. We dig in depth, how the intelligence of lower levels could be raised. The traditional ripple control can not be extended on a lot of programmable household appliances, as the washing machine, refrigerator, tumble drier, etc. We investigated typical households and found a great voluntary control potential. The paper presents the measurement results and gives a structure to take these loads into a "smooth" DSM.
\end{abstract}

Keywords - DSM, Intelligent Energy delivery system, Modelling of the power system, Household Loads, Smart Grid

\section{OBJECTIVES}

Nowadays we face the incredible increase of the energy demand all over the world. The unconditional satisfaction of the hardly schedulable load demand led us close to the limits of resources, economical viability and environmental sustainability. The EU encourages searching solutions in the frame Intelligent Energy Europe program.

There is a great capacity reserve at generation and transmission part of the load is more balanced, if the peak/valley ratio approaches the 1 . Without Demand Side Management (DSM) this ratio is close to value 2. Although there are many DSM techniques (tariff control, campaigns, scheduling techniques) practically the ripple control is spread over. We work on the exploitation of more DSM capabilities and looking for new control structures.

To overcome these problems the power system must be made more active, the generation and the load must cooperate, there is a need for intelligence in power systems.

\section{THE INTELLIGENCE IN POWER SYSTEM}

\section{A. Power system level}

The age of power system technology is close to a hundred years and the traditional control tool palette was extended in the last thirty years by different Artificial Intelligence based applications in the control centres [1]:

- $\quad$ Alarm filtering and processing

- Fault analysis and equipment diagnosis on the network

- Remedial actions, system restoration

- Security assessment (static and dynamic stability)

- Load- and generation forecast [3]

- Planning and scheduling the load and production

- Electricity market operation

- Training simulators

- Different optimisations (loss, security, generation, network configuration [2])

- Unit commitment,

- Maintenance scheduling

- Decision support, etc.

Operations in the deregulated market:

- $\quad$ Strategic bidding

- $\quad$ Price forecasting

- $\quad$ Congestion management

- Portfolio management

- $\quad$ Market forecasting, etc.

Realizing these functions different intelligent techniques are used:

- Artificial Neural Networks (ANN)

- Fuzzy sets

- $\quad$ Expert systems

- Multi agent systems

- Constraint programming

- Pattern matching, etc.

All the functions are realised (wide area) SCADA systems. 


\section{B. Local or regional customer level}

The Intelligent Energy and Smart Grid topic covers some lower level aggregation of small loads and resources (typically DG REN sources, as microturbines, micro-hydros, small wind turbines and photovoltaics and intelligent loads as self controllable air conditioners, dryers, washing machines and electric bread baking machine) that are scheduled and controlled on low level. These partial grids (semi microgrids or virtual microgrids [4]) can be counted as an intelligent part or an intelligent load of the network.

At the demand side the ripple control has been widely used for decades. This is a rough, unintelligent, time based remote switching technique.

There are two groups of load that can be made "intelligent":

- Medium size, concentrated customers, as malls, office buildings (towers) and compact residential areas. Each one represent 0,5-3 MW load.

- Small scale customers are typically the households, with 3-20 kW peak load. One household does not disturb the power system, but thousands represent hundreds of MW-s. That is why it worth to deal with them.

\section{MEASURING OF THE CONSUMER HABIT}

We concentrate on the second group. The households may contain three sections of electrical appliances:

- $\quad$ Non reschedulable, spontaneous loads, as the hair drier, TV set, radio, telecommunication devices, modems, lighting, iron, microwave oven, coffee machine, computers, cooking plate, etc.

- The water heating boilers and the electric heating is remotely controlled by ripple control for decades

- We concentrate on the third group that represent a great load potential, but the usage attitude makes possible the voluntary reschedule of the normal usage schedule. These are the washing machine, tumble drier, refrigerator, cooler, air conditioners, electric bread backing machine and the heat pump.

These loads can be theoretically delayed or rescheduled from peak time to valley.

We performed measurements on different households. We used analytical and statistical methods, too. (Details should be described in the full length paper.) We found that the present ripple control did not alleviate the peak problems (see Fig. 1.) That is why we recommend to use better the present DSM tool (see Fig. 2.).

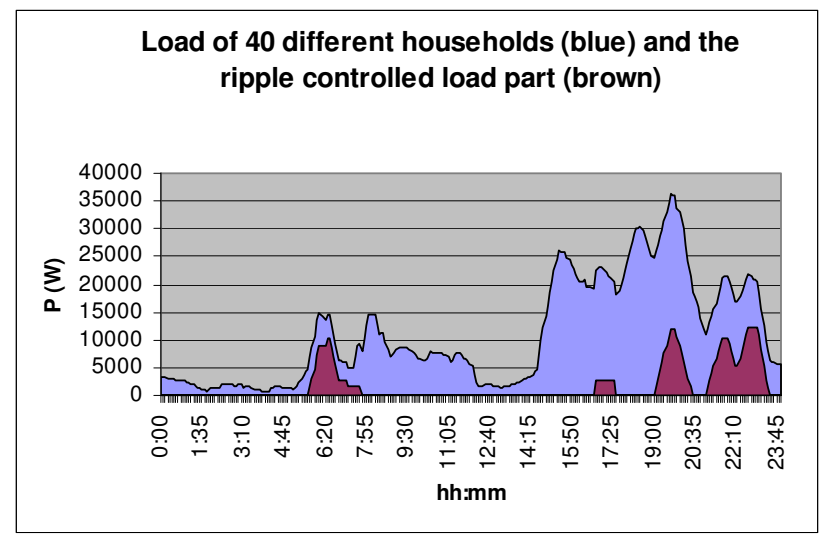

Fig. 1.: Original DSM

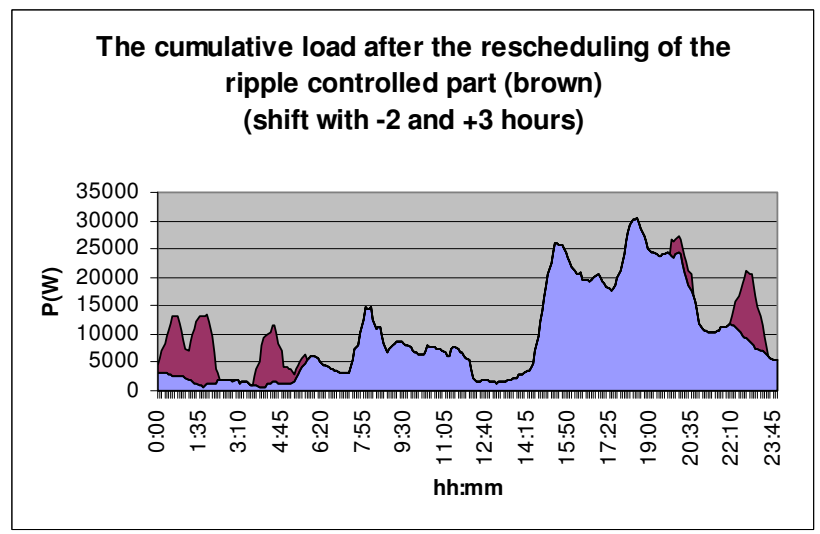

Fig. 2.: Rescheduled ripple control

After deeper analysis we found that the reschedule potential is over $50 \%$ in an average house hold (see Fig. 3.). After rescheduling half of the potential, the peak decreased more than $30 \%$ (see Fig. 4.)

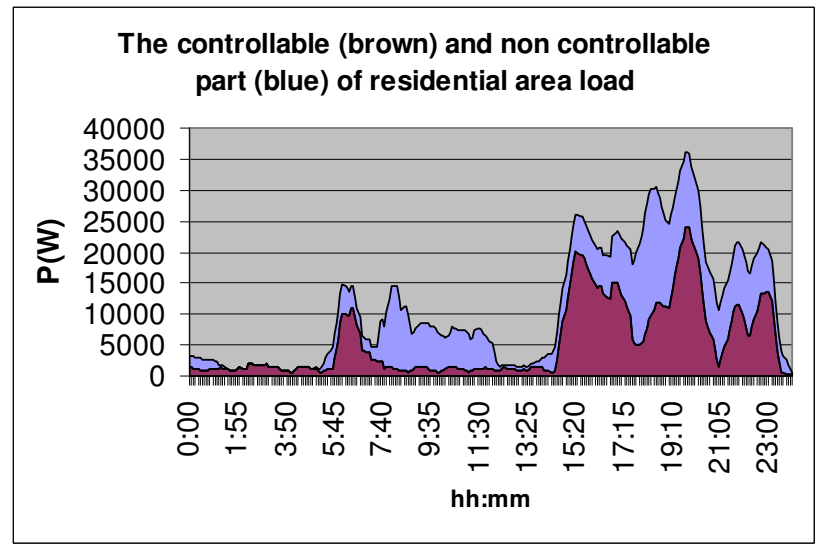

Fig. 3.: The two parts of the load 


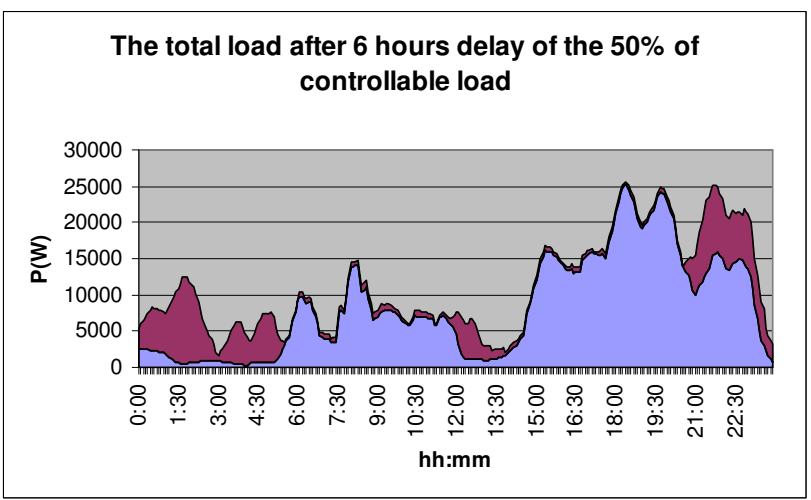

Fig. 4.: A proposed voluntary rescheduled load curve

\section{REALISATION OF THE RESCHEDULING PRINCIPLES}

As one can see, there is a huge reserve in the household load reschedule. This task requires local hardware elements in each household, communication networks, control centers and a control strategy.

The loads and the reschedule possibilities can be monitored by special additive hardware units. These provide information from the household to the local control machine (e.g. 1 unit / flat) and these can activate the commands of the remote control, too.

Fig. 4. shows the different intelligence functions which can be built in (or close to) the small generators (microturbines or small wind turbines and PV), storage devices (flying wheel or accumulator) and loads (washing machine, drier, etc.).

\begin{tabular}{|l|}
\hline \multicolumn{1}{|c|}{ Schedule center } \\
-Monitoring of \\
generation capabilities \\
-Monitoring of load \\
demand \\
$\cdot$-Global load forecast \\
-Generation optimisation \\
-Scheduling \\
- Load control \\
- Logging, evaluation \\
-Connection with the \\
system operator \\
\hline
\end{tabular}

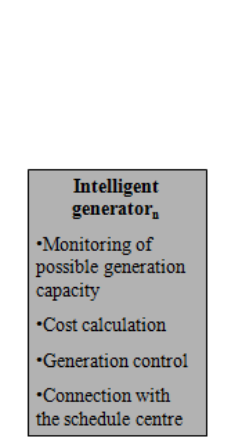

Fig. 5.: Local intelligence functions

The local intelligence units can be connected to a low level center, in radial organisation (Fig. 6.)

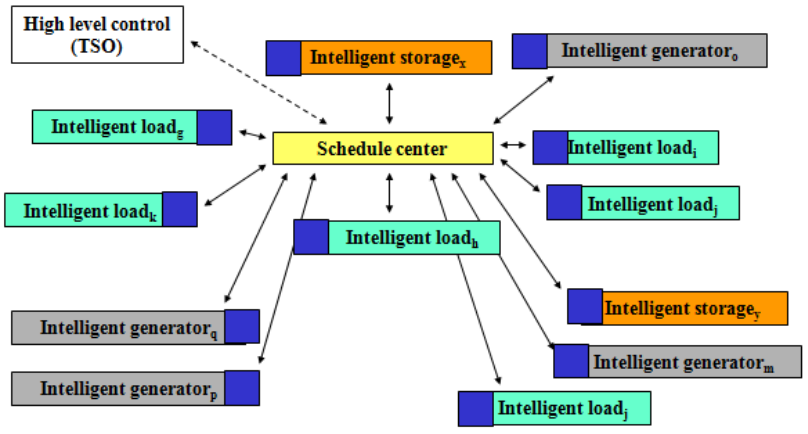

Fig. 6.: Low level center and the household units

At Budapest Tech an $\mathrm{R}+\mathrm{D}$ work for the development of local intelligent units has been started [5.]. The following picture shows the equipment that measures the power and quality values and the data are transmitted through GPRS connection to the center. (The development was supported by the grant GVOP3.3.3-05/2.-2006-01-0118/3.0).
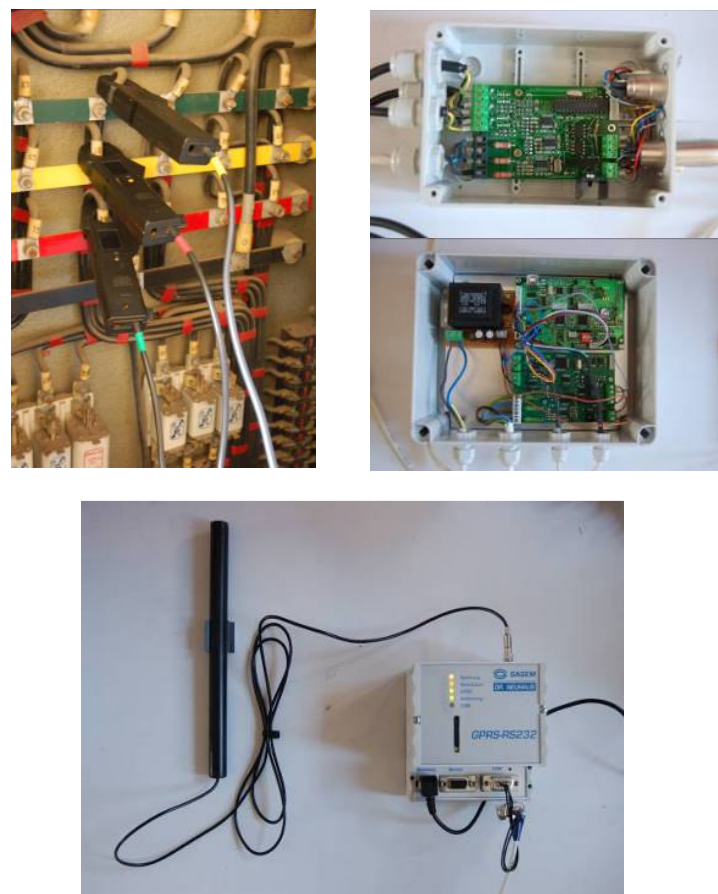

Fig. 7.: local data capture and the GPRS data connectiont 


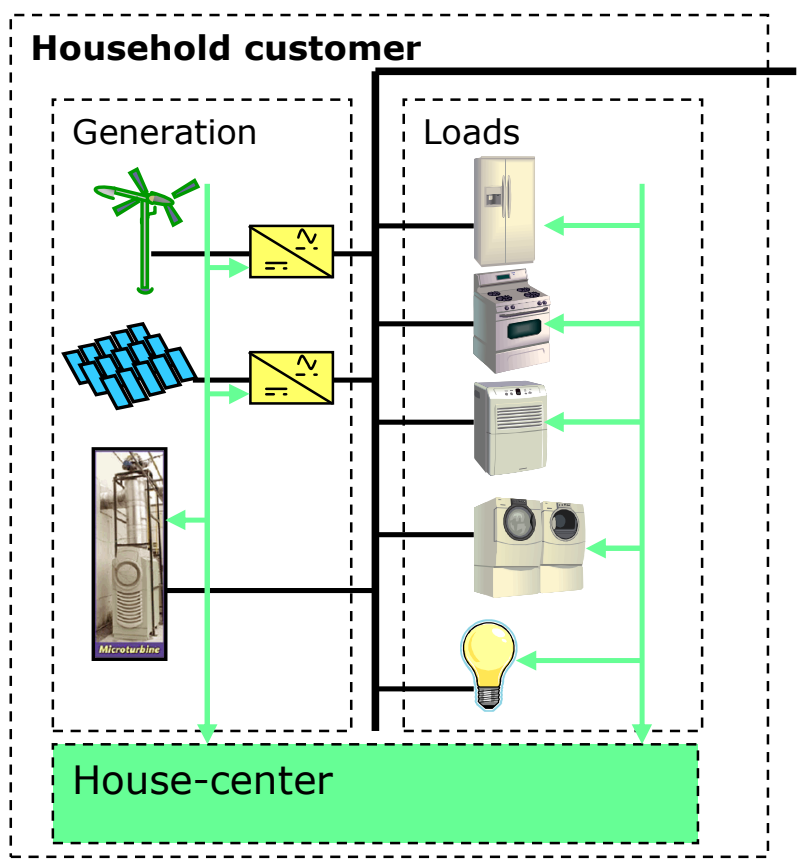

Fig. 8.: Data interface screen and household remote measurement

Fig 8. shows a possible household energy center that handles the local equipments [6.]. These data can be monitored by the previously introduced GPRS device. A remote data interface screen is shown on Fig. 9. Figure 10. gives a real remote measurement of a night load curve with the operation of a bread baking machine.

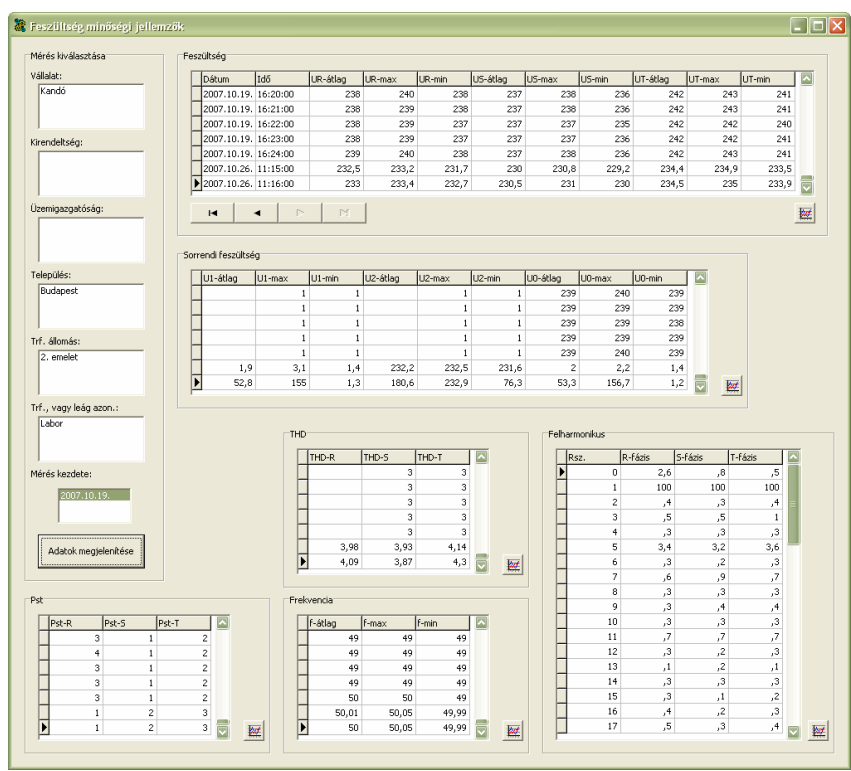

Fig. 9.: Data interface screen of remote measurement

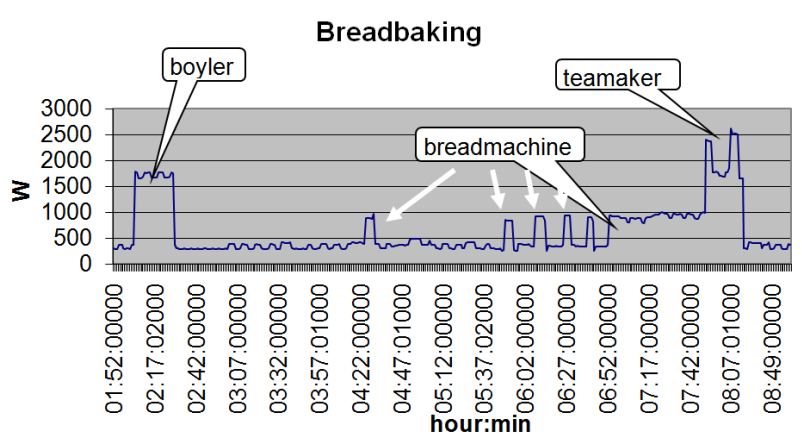

Fig. 10.: Household remote measurement

\section{A. The communication}

Nowadays we are working on the development of a low level co-operation network. In this data exchange the intelligent end-user load and small generator units communicate. The communication must

- be semi secure (public internet with security codes)

- hold short-term information (typically one day, but it can be only some hours too)

- have some redundancy

- $\quad$ pass time slice info instead of daily curves

- be asynchronous communication

- $\quad$ have cyclic information update (load and generation forecast, state of the storages)

The normal communication sequence is the following:

1. Inquiry from the control centre

2. Capability message from the load/generator/storage

3. Capability updating messages from the devices

4. Command from the control centre

5. Fact message from the load/generator/storage

The central „Inquiry” message from schedule centre $->$ to intelligent load/generator/storage, initiated by the schedule centre:

- Unit ID

- $\quad$ Date (YYYYMMDD)

- Time (serial number of the $1 / 4$ hour in the day - 196)

The „Capability” message from the intelligent load/generator/storage $->$ to schedule centre. This is the answer for inquiry of stand alone devices.

- Unit ID

- Unit type $(\mathrm{G} / \mathrm{L} / \mathrm{S})$

- $\quad$ Date (YYYYMMDD)

- Time (serial number of the $1 / 4$ hour in the day - 196)

- Max active power capacity (P)

- $\quad$ Min active power capacity (P)

- $\quad$ Max reactive power capacity (Q) 
- $\quad$ Min reactive power capacity $(\mathrm{Q})$

- Active power price (cent/kWh)

- Reactive power price (cent/kvarh)

The "Command" message from schedule centre $->$ to intelligent generator/load/storage.

- Unit ID

- Unit type (G/L/S - for redundancy)

- Date (YYYYMMDD)

- Time (serial number of the $1 / 4$ hour in the day -1 96)

- $\quad$ Production / load / storage command (P)

- $\quad$ Production / load / storage command (Q)

The „Fact” message from intelligent load/generator/storage $\rightarrow$ to schedule centre. This is the answer for inquiry of after the past performance of the local equipments.

- Unit ID

- Unit type $(\mathrm{G} / \mathrm{L} / \mathrm{S})$

- Date (YYYYMMDD)

- Time (serial number of the $1 / 4$ hour in the day - 196)

- $\quad$ Active power fact $(\mathrm{P})$

- Reactive power fact (Q)

- Active power price (cent/kWh)

- Reactive power price (cent/kvarh)

\section{B. The control strategy}

The system can have different objectives:

- decrease the peak/valley ratio on energy system level

- optimize the self supply, the better exploitation of renewable sources [4]

- increase the local profit, etc.

By setting up the previously introduced system, any active or passive Demand Side Management (DSM) strategy can be realized.

\section{Would it be mandatory or voluntary?}

Technically the load-rescheduling can be easily realized. The key factor of the operation is the interest vindication. If an appropriate business model is set up, the players will regulate themselves by their interests. The energy authoritsation, the legislation has to create an environment, where the small customers and generators can gain money if the play this self regulation game. A possible solution is the tariff control that is parties are aware of the price difference between the peak and valley energy. This implies the need for the central information dissemination about energy situation (lack or surplus).

\section{CONCLUSION}

The unlimited growth of power demand requires the technically intelligent cooperation between the electricity producers and users. We investigated the Demand Side Management capability in the small households and we found a huge technical potential.

We provided a control strategy and a hardware realisation scheme. We are convinced that this type of solution makes the network smart and intelligent, so we contribute to the sustainable electricity supply.

The author thanks to the students of the Budapest Tech for the support in the data collection and measurement.

\section{REFERENCES}

[1.] Z. A. Vale, Intelligent Power System in Wiley Encyclopaedia on Computer and Software Engineering.

[2.] O. Geyrisman, Optimum distribution switching in TD World September, 2007, p 46.

[3] T. Bessenyei, Estimation of Country-Wide Wind Power Generation Based on Meteorological Data in proceedings of International Conference on Communication, Computer and Power (ICCCP'07), Muscat, Oman, February 19-21, 2007; pp 177-181

[4.] P. Kadar, Testbed for virtual microgrid control strategy development in Proceedings of International Conference on Renewable Energy and Power Quality (ICREPQ'07) Sevilla, Spain, March 28-30, 2007

[5.] F. Badacsonyi, Simulation of power electronics in the education, Proceedings of VIth International conference of Science and Practice, Budapest 2000, 7-16

[6] T. Bessenyei, Communication with intelligent household equipments, Proceedings of Intelligent Energy Systems Conference, Budapest, November 27. 2007 